\title{
Organic Collaborative Teams: The Role of Collaboration and Peer to Peer Support for Part-Time Doctoral Completion
}

\author{
Cathy M. Littlefield \\ Peirce College, \\ Philadelphia, PA, USA \\ clittlefield@peirce.edu
}

\author{
Laura M. Taddei \\ Neumann University, \\ Aston, PA, USA \\ taddeil@neumann.edu
}

\section{Meghan E. Radosh \\ Widener University, Chester, PA, USA}

\section{meradosh@widener.edu}

\begin{abstract}
With doctoral completion rates hovering around $50 \%$, students, faculty and institutions are seeking methods for improvement. This narrative inquiry examined the impact of collaboration and peer to peer experiences on doctoral completion of three peers in a part-time doctoral program. Prior to this inquiry, minimal research existed on the impact of peer to peer support and collaboration on doctoral completion; therefore, the three peer authors defined, described, and recommended ways to encourage organic collaboration. The authors' defined organic collaboration as a naturally-formed dynamic peer to peer support group, built on individual strengths and differences, while focused on a common goal. Themes found during the narrative inquiry included the identification of a common goal, amicable group dynamics, peer to peer support, and intentional relational learning. The peer authors provided practical knowledge on ways students, faculty and higher education institutions can benefit from encouraging and supporting organic collaboration. This narrative inquiry demonstrated the long-term benefits of peer to peer support and collaboration that led to scholarly, professional, and personal support.
\end{abstract}

Keywords: Peer to peer support, part-time doctoral completion, organic collaboration, intentional relational learning, narrative inquiry, group dynamics

Material published as part of this publication, either on-line or in print, is copyrighted by the Informing Science Institute. Permission to make digital or paper copy of part or all of these works for personal or classroom use is granted without fee provided that the copies are not made or distributed for profit or commercial advantage AND that copies 1) bear this notice in full and 2) give the full citation on the first page. It is permissible to abstract these works so long as credit is given. To copy in all other cases or to republish or to post on a server or to redistribute to lists requires specific permission and payment of a fee. Contact Publisher@InformingScience.org to request redistribution permission.

\section{Introduction}

Completion rates among doctoral students remain an ongoing issue in higher education institutions (Gardner, 2010; Holley \& Caldwell, 2012; Holloway \& Alexandre, 2012; Jairam \& Kahl, 2012; Jaschik, 2007; Kania-Gosche, Leavitt, \& Wisdom, 2011; Lahenius, 2012; Mullen \& Tuten, 2010). Research has shown 
that, within the United States, there are a staggering 100,000 individuals working to complete their doctoral degree, but an alarming $50 \%$ of those individuals will not succeed (Jairam \& Kahl, 2012). Much of the research on doctoral completion rates link various factors to student failure or success. For example, Jairam and Kahl (2012) found that doctoral students face many stressors, such as "relative poverty, anxiety, sleeplessness, academic demands, fear of failure, examinations, and time constraints" (p. 312) but, on the contrary, a relevant stress release may be attributed to socialization among doctoral students striving for degree completion. Jairam and Kahl (2012) revealed doctoral student socialization generates various types of relationships that help to relieve stress and anxiety while providing academic support.

While previous research has focused on the completion rates of doctoral students, very little has been done regarding the role of peers in doctoral programs (Flores-Scott \& Nerad, 2012), as well as the doctoral students as adult learners (Mullen \& Tuten, 2010). Many factors can contribute to the successful completion of doctoral students, including the pedagogical use of student teams. Beyond the scope of higher education, teamwork has been defined as "a cooperative process that allows ordinary people to achieve extraordinary results" (Scarnati, 2001, p. 5). In the realm of higher education, specifically doctoral education, student-based teams are often created or identified by faculty for the purposes of completion of an assignment, then disbanded at the conclusion of the course (Macke \& Tapp, 2012). While the value of a student-based team seems logical, minimal research exists illustrating the long term benefits of these student teams on the completion of a doctoral program. This lack of literary support prompts two questions: at what point does an instructor-identified team formed for a single course project, transcend into a collaborative team that fosters and supports doctoral completion? And, is it possible the prospect of this collaborative team is what could improve the progression of doctoral students through the often isolating dissertation phase, and subsequently positively impact completion rates? The peer authors experienced this type of collaboration during their doctoral program, which occurred in a naturally evolving, rather organic way. Consequently, the purpose of this narrative study is to define and examine the role of organic collaboration and peer to peer support on part-time doctoral student completion.

\section{Background}

The authors are three peers, Meghan, Laura, and Cathy, each balancing work, family, and busy lives, while participating in a part-time, non-cohort higher education leadership doctoral program. The resulting narrative study was designed to capture the organic collaborative experiences of these three peers in their doctoral program which ultimately led to their degree completion. Throughout this experience, the peers contributed to these collaborative efforts by creating intentional peer relationships during the comprehensive exam preparation, dissertation process, and post-doctorate scholarly practices. This narrative is the story of an organic collaboration among three peers who were united by their instructor in one course, but remained intact to this day by choice. While each of these peers was strong academically and would have completed the program in due time, each peer's strength, when combined with the others, contributed to the strength of the organic collaborative team.

The organic collaborative team consisted of Meghan, Laura, and Cathy. Provided below is a short description of each member:

Meghan started her doctoral career during her tenure as a higher education administrator in her institution's alumni engagement department. She started the doctoral program in the Fall of 2006 taking one course at a time to balance classroom, work, and life. Several semesters after starting the doctoral program, Meghan increased her course load to two classes each semester, got married, purchased a home and moved, all while working fulltime. Even though she started the program enrolling in one course at a time, leading to a 
longer program projection than her other peers in this article, this varied path serendipitously placed her on the same program projection, time-wise, as Laura and Cathy. Meghan successfully completed her doctorate in Spring of 2013.

Laura was working part-time as an adjunct professor teaching early childhood courses in higher education and decided to pursue her doctoral degree on a part-time basis. Laura began her program in Fall of 2008, taking two courses every semester including summer. Her oldest child was 16 at the time and her twins were 6 and in first grade. Within the first year of her doctoral program, Laura began a full time position at a two-year private higher education institution. Laura's goal was to complete her doctorate before her oldest son graduated college with his bachelor's degree. Laura successfully completed her doctorate in March 2012 and her oldest son completed his bachelor's degree in May 2014.

Cathy, an entrepreneur with no prior higher education work experience, aspired for a career in higher education as a full-time faculty member. She began her doctoral program in January 2008 on a part-time basis while she balanced owning and operating a business with her husband, and raising two young children under the age of six. Her dream was always to combine her educational knowledge with years of business experience in a college classroom. By her second semester in the doctoral program, she increased her course pace by enrolling in two courses at a time. In addition, within her first year in the program, Cathy began as an adjunct professor in the continuing studies division of the university in which she was enrolled. She continued working full-time for herself, teaching part-time for the university, raising a family, and taking courses until the completion of her program. In August, 2012, Cathy successfully completed her doctorate.

In Fall 2009, Meghan, Laura, and Cathy were placed on their first instructor-identified team for a team-based project. The chemistry among the three peers formed a lasting bond, resulting in the organic collaborative team as defined below.

\section{Definition}

For the purpose of this study, the peers defined organic collaboration as a naturally formed dynamic peer to peer support group, built on individual strengths and differences, while focused on a common goal. As a team of peers, the common goal started as the completion of a team-based assignment; progressed as support and collaborative study sessions in preparation for the comprehensive exams; followed by the completion of their individual dissertations and program completion. This common goal continues beyond program completion as they pursue scholarly research together. When asked independently of one another to define organic collaboration, Meghan described organic collaboration as a group of individuals that come together on their own accord to work together to meet a common goal; Laura characterized an organic collaborative team as a peer group which is not forced or predetermined, and one in which all team members want to be a part of this collaboration; and Cathy identified it as a self-selection of peers that occurs by trial and error, while blending various personality types and leadership styles, all for a common purpose. Even though portions of each of the peer's definition emerged during the study, the literature was void of any reference to organic collaboration; therefore, Meghan, Laura, and Cathy defined themselves as an organic collaborative team.

\section{Literature Review}

The Council of Graduate Schools (2014) is in the midst of a multi-phase seven-year project researching $\mathrm{Ph}$.D. completion and attrition rates. Findings thus far found an unfavorable prospect for doctoral students with less than $75 \%$ of students entering a $\mathrm{Ph}$.D. program persist to completion (Council of Graduate Schools, 2014). Furthermore, the Ph.D. Completion Project found 80\% 
of the participants identified financial support as the top incentive toward timely completion, $63 \%$ cited mentoring/advising as incentive, but only 39\% identified peer support as a motivating factor leading toward degree completion. Kania-Gosche et al. (2011) asserted that earlier phases of the Ph.D. Completion Project emphasized the need for "more support for students during the dissertation writing phase" (p.1). However, as the name implies, the Project focused only on Ph.D. students, primarily in the fields of engineering, life sciences, math and physical sciences, social sciences, and humanities. Storms, Prada, and Donahue (2011) addressed doctorate in education (Ed.D.) completion and contend completion rates frequently stall between the points of course completion and dissertation defense. Another distinction in the case of education, the demographics of Ed.D. students often differ from those of Ph.D. students; Ed.D. students are "admittedly a different population than typical Ph.D. students" (Butin, 2010, as cited in KaniaGosche et al., 2011, p. 2).

Kania-Gosche et al. (2011) identified a gap in the literature dedicated to the study of Ed.D. programs, and found typically that Ed.D. students experience a gap of many years between completion of a masters and the pursuit of a doctorate. Additionally, Ed.D. students are often adult learners who have families, financial obligations, and work full-time. Due to the nontraditional nature of the Ed.D. student, the isolation felt during the dissertation stage and need for support can be more pronounced (Kania-Gosche et al., 2011). As such, nontraditional doctoral programs are designed to meet the needs of the adult learner; specifically, the scholarly practitioner. According to Radda (2012), nontraditional doctoral students bring "15-25 years of professional experience ... [along] with masters degrees and significant knowledge and experience in their current field of practice" (p. 50). Furthermore, these doctoral students need opportunities to interact in a scholarly environment that does not revolve solely around classroom interactions. Radda (2012) identified the need for scholarly learning communities that assist nontraditional doctoral students in connecting beyond the classroom. He described a concept called the Doctoral Community Network, which provides nontraditional doctoral students opportunities to collaborate with peers virtually. The Doctoral Community Network is an online scholarly network which assists with connecting doctoral students with other nontraditional students to facilitate informal discussion and interactions, thus forming a collaborative community of learners.

Collaboration is a key component to academic success and student performance, especially within higher education doctoral programs. Collaboration has been shown to improve the completion rate of students due to an increase in socialization within the academic program. Anderson (1996) noted, "It is important, therefore, for those who would enter academic life, namely doctoral students, to participate in collaborative efforts as part of their education and socialization" (p. 306). Additionally, Pemberton and Akkary (2010 ) concluded: "Studies on program completion show that peer relationships, in the form of meaningful professional and personal connections, are associated with increased motivation for learning, persistence in the face of challenges, and success in program completion" (p.180). Group work and collaboration can benefit the individual student because it "provides a shared workload, shared ideas, shared deadlines that help to increase momentum on a project" (Anderson, 1996, p. 307).

Collaborative pedagogy has the ability to facilitate learning in a student-centered forum in the context of project-based, case-based, inquiry-based and problem-based scenarios (Oliver, 2001, as cited in Tarricone \& Luca, 2002). Furthermore, collaboration "relies upon individuals working together in a cooperative environment to achieve common team goals through sharing knowledge and skills" (Tarricone \& Luca, 2002, p 641). Successful teams exude a synergistic energy in which all members contribute and participate, while remaining flexible and adaptable to a cooperative work environment while all striving for a common goal, rather than an individualistic effort and competitive environment. Successful team characteristics among members have the ability to predict collaborative success (Tarricone \& Luca, 2002). 
It is important to note that while teamwork and collaboration are similar, they are not necessarily synonymous. Silverstein (as cited in McLeod, 2010) emphasized, "Teamwork and collaboration are cousins, but they are not twins" (para. 8). Differences between the two are based on structure and flexibility. Teamwork exists in a hierarchical structure, thereby influenced by an authoritative figure such as a professor or coach. Campbell (2011) identified a team as those grouped by a manager who "work closely together to achieve a joint outcome ... [and act] interdependent, but they are fully committed to a single result" (para. 3). He continued, teams "need to reach joint decisions ... [and] will be cautious about taking unilateral action without checking with each other to make sure there are no negative side effects" (Campbell, 2011, para. 3). Team members may dislike each other, but as long as the authoritative figure has the ability to resolve disputes, the team may be successful (Campbell, 2011). In the realm of academia, a professor designs a team project, sets expectations, timeline, and requirements. All students are aware of expectations and requirements for success and, ultimately, the professor remains the authoritative figure (McLeod, 2010). Collaborators, according to Campbell (2011), share goals, but those goals are "usually only a small part of their responsibilities. Unlike a team, collaborators cannot rely on a leader to resolve differences" (para. 5). A successful collaboration "requires emotional engagement ... and participants have a high respect for each other's competence on the topic of the collaboration" (Campbell, 2011, para. 8).

When it comes to examining the effects of collaboration and peer impact on graduate/doctoral students, minimal research has been completed within this subject (Devenish et al., 2009; FloresScott \& Nerad, 2012). Anderson (1996) stated that collaboration, or group work, is beneficial to doctoral students in three ways. First, it provides an outlet in which students will be exposed to "critical secondary expertise" (p. 310) thereby allowing doctoral students to expand their own knowledge and skills. Second, it provides social benefits outside of the classroom and connects peer to peer, and peer to faculty interaction. Lastly, it provides doctoral students with a deeper connection and network within their academic program (Anderson, 1996). The main component of collaboration is a social foundation. Gardner's (2010) study on the impact of socialization and completion rates in doctoral programs found that successful programs offered the greatest opportunity for students to form such social relationships. Students within Gardner's study reflected on their academic programs and identified their peers and faculty as "family" (Gardner, 2010, p.69).

Despite the family effect felt by some, collaboration may come with its share of downfalls for other doctoral students. Some doctoral students find collaboration cumbersome when problems arise with a project or within the group (Anderson, 1996). Devenish et al. (2009) stated that within a group setting, students can fear that individual student voice would be diminished over the group voice. Furthermore, group dynamics can suffer when members of the group are not contributing or putting in the same effort as others in the group, or competition might arise with authorship credit, especially when it comes to academic work (Anderson, 1996; Pemberton \& Akkary, 2010). While collaboration and group work can foster negative implications for the individual student, the benefits outweigh its drawbacks.

Traditionally, collaboration within doctoral programs is often utilized in disciplines where the work was deemed beneficial to both the student and faculty (Anderson, 1996). Additionally, Anderson (1996) described collaboration as "not only a structural work arrangement but also a means for enhancing students' socialization to academic life" (p. 321). Many doctoral programs utilize the cohort model in which students enter a program of study and remain intact as a group throughout the progression of coursework (Pemberton \& Akkary, 2010). Even though much of the research on graduate and doctoral program collaboration is often focused on examining the impact or development of cohort model programs, Mullen and Tuten (2010) found that, although often rare within academic programs, self-created peer to peer cohorts impacted student progress. 
McLeod (2010) defined collaboration as a function of a peer-based, self-directed structure which evolves over time, requires flexibility, and frequently changes based on fluxing situations. Collaboration is "about coming together and putting your best ideas in the service of something bigger than yourself" (McLeod, 2010, para.23). Furthermore, Campbell (2011) identified three attributes of successful collaborations as evidence and commitment of an emotional engagement, high levels of respect among collaborators, and freedom to use creativity as a way to advance the collaborative efforts. Amabile et al. (2001) stated collaborative success also includes the presence of a project-relevant knowledge, and common attitudes and motivation.

Collaboration at the doctoral program level has a specific program focus of education, research, and dissertation completion. Anderson (1996) found that graduate programs that include collaboration have benefits such as preparation towards research and is a "means for enhancing students' socialization to academic life" (p. 321). Doctoral program collaboration strategies such as intentional relational learning, communities of practice and doctoral student mentoring programs can impact doctoral student success and completion. Intentional relational learning provides opportunities to encourage collaboration and reciprocity among faculty and students and peer to peer where sharing of ideas are encouraged and competition is discouraged.

These distinctions provided the transitional context from what started as an instructor-identified team assembled for a single assignment, to the collaborative relationship that emerged as an organic collaborative team of peers.

\section{Methodology}

Narrative inquiry, as a qualitative research method, is focused on examining and categorizing human experience through shared stories (Connelly \& Clandinin, 1990; Creswell, 2006). This narrative inquiry, conducted by these three peers, examined their organic collaboration experience in a higher education doctoral program and shows implications for the impact of such collaboration on doctoral student success. By using a narrative inquiry approach it allowed the peers, as researchers, to reflect on their experience, both on a social and personal level, and use their experience to provide practical knowledge for institutions, doctoral programs, and student collaboration (Conle, 2000).

As a means to capture their individual reflections, the peers developed a reflective questionnaire that was used to provide a structure to their stories. Interpreting stories and reflections "is at the heart of narrative analysis" (Patton, 2002, p. 118). The questions were as follows:

Describe your experience as you first became involved in this team?

What kinds of attributes existed among team members?

What impact, if any, did your team members have on your doctoral completion?

Describe the characteristics of your team - what makes the team successful? Were there times when collaboration was difficult? Please be specific and describe.

Describe examples of peer to peer support that you experienced during your team experience?

How did faculty encourage collaboration and networking?

How did the institution support peer collaboration?

What suggestions do you have for the institution, faculty, or other doctoral students regarding organic collaboration?

How would you define organic collaboration? 
These reflective questions prompted each peer to reflect on their organic collaboration experience and the impact it had on their doctoral student experience.

The collected peer responses were then reviewed using the constant comparative method allowing the peers to compare their reflections for similarity, consistencies, and themes (Creswell, 2007; Merriam, 1998). By using the constant comparative method, the peers were able to identify four key organic collaboration themes: common purpose, group dynamics, peer to peer support, and intentional relational learning.

Connelly and Clandinin (1990) described narrative inquiry as "a process of collaboration involving mutual storytelling and restorying as the research proceeds" (p. 4). During the data analysis, the three peers met on several occasions to discuss the data, share personal insights and discoveries allowing for additional reflection, and the peers to expand upon the narrative inquiry.

\section{Findings}

The collaborative experience of the three peers, Meghan, Laura, and Cathy, illustrated that such peer to peer collaboration provides key characteristics that helped each member to doctoral program completion. Gardner (2010) stated that collaboration provides peer support that can prove to be beneficial in helping doctoral students reach their completion goal. While this organic collaborative team's experience echoed the literature, four distinct themes emerged: uniting for a common purpose, possessing amicable group dynamics, providing peer to peer support, and creating intentional relational practices.

\section{Theme One - Common Purpose}

In the early days of the peers' collaborative activity, the three peers were assigned to a team by the instructor. At that time, the common purpose was simply successful completion of the assignment. Since the peers were participating in a non-cohort program, this was the first time they were enrolled in the same course. Within a few weeks, the assignment was presented to the remainder of the class and the peers received positive feedback from the instructor. A bond was formed and continued to strengthen as the peers were occasionally classmates in future courses.

In non-cohort learning environments, use of team projects is an effective pedagogical approach that fosters this socialization among students (Mullen \& Tuten, 2010). Although Meghan, Laura, and Cathy worked together on the instructor-identified team within the class environment, the continuation of the collaborative interactions occurred voluntarily beyond the scope of the classroom and was not centered solely on classroom interactions, as echoed by Radda (2012). Coincidentally, despite their varied course trajectories, the three peers reached course completion at the same time, and the preparation for comprehensive exams united them for a common goal.

Similar to the research of Amabile et al. (2001) on the need for common attitude and motivation, these peers found that their common goal of doctoral completion was a key factor in their team coming together organically. For Meghan, having a common goal made her organic collaborative team experience, and all that work and effort, that much more special. She described that doctoral programs can be such an individual process; however, by forming our organic collaborative team it enhanced the shared experience, often felt in a classroom setting, throughout the whole program. Meghan felt that her team helped to keep her focused on the end goal, motivated to do her best, and assurance in knowing that there is always someone to turn to who will understand her struggles. She added that getting a doctorate is hard work, and having peer support makes all the academic challenges that much easier to conquer. Meghan described this team as having a shared goal, "to completing our degrees", and she continued: "Sure, this goal was also an individual goal, and we had our own ways of getting there at times, but the connection kept us going." 
As Tarricone and Luca (2002) alluded, collaboration can be the impetus for common goal achievement. Laura agreed when she stated: "We all wanted to succeed. Everyone was willing to provide a helping hand when needed and there was never a feeling of competition." Although all peers had different personalities, the diverse personalities seemed to work well together.

\section{Theme Two - Group Dynamics}

Campbell (2011) described the attributes necessary for successful collaborative efforts as respect, creativity, mutual encouragement, and support. Pemberton and Akkary (2010) asserted the absence of competition is necessary for collaborative success. Essentially, group dynamics are effective when all members contribute fully and equally. Cathy acknowledged:

I would have completed my degree regardless, but the impact of our organic collaboration gave me the strength of a study group for comps, as well as being a sounding board, shoulder to lean on, and source of encouragement and support, but most importantly, I had an opportunity to help them in return. This experience was not about ME completing the program, it was about getting all three of us completing the program.

For Meghan, the group dynamics provided her with a level of comfort, similar to that of a family, and provided a sense of familiarity. "The first time we worked together it just clicked. We were able to come together and share ideas openly. We were open to each other, the way we worked, and our ideas." She continued: "It was apparent that we were a group that had energy, which helped to keep motivation going. It turned what could have been an assignment to complete into something that was an enjoyable learning experience."

The group dynamics Meghan, Laura, and Cathy experienced illustrated Gardner's (2010) "family" characteristic through their lasting friendship and support. Prior to each of them completing their dissertations, the support was in the form of encouragement, advice for how to approach various situations, and being a cheerleader for each other. Cathy explained: "Post dissertation, the support is still amazing, but more in a friendship context. Each of us has great respect for the others and that in itself is support."

The peer's organic collaborative team displayed diverse group dynamics such as providing support, encouragement, strength, intelligence, focus, determination, commitment, accountability, and socialization. The peers were three different people who were each strong individually, but when working together, the team was even stronger while complementing each other's style in a powerful way. Meghan, Laura, and Cathy's group dynamics allowed for a level of openness to each other's ideas and concepts which provided an environment in which to share their individual voices without fear of being unheard. Devenish et.al. (2009) found that students working in a team or group setting feared a loss of voice. This notion was not evident among the organic collaborative team of Meghan, Laura, and Cathy.

\section{Theme Three - Peer to Peer Support}

Peer to peer support was an emergent theme from this narrative study. As stated previously, minimal research has been completed on the role of peers in doctoral education (Devenish et al., 2009; Flores-Scott \& Nerad, 2012). Meghan, Laura, and Cathy depended on each other for support and encouragement throughout their journey. Cathy provided an example of this support as follows:

The entire comprehensive exam experience provided opportunities for major support at all times. If any of us felt as though we were struggling to grasp a concept, the whole team would focus on that area until it was understood. At the same time, the review helped to reinforce each of our understanding of the particular concept. 
Although each was self-directed and motivated, the peer to peer support provided a place to turn if in need of encouragement and advice. Beyond comprehensive exams, the peers provided support as each reached the dissertation proposal defense, and later dissertation defense stages of the program. Meghan agreed:

We cheered each other on and checked in often to make sure we were moving along. I took the longest in getting this date, but they were behind me to keep my spirits up. We were there for each other through each step, celebrating each small victory, leading to the greatest victory of all; the successful dissertation defense.

The peers' mutual support was a common occurrence, being present for each other to wish each other good luck prior to, and congratulations after, the successful defense. Essentially, each successful defense was a victory for the team.

Meghan, Laura, and Cathy have continued to learn and work together through writing publications and presentations. Although each peer has a separate career path, they continue to collaborate on academic and scholarly interests. When working together, the peers remained enthusiastic, flexible, and supportive of each other. Laura described the impact of peer to peer support as being "imperative for preparing for comprehensive exams." She continued: "Everyone contributed equally when having questions regarding research-specific questions. I received peer to peer support when working on my dissertation, and even while writing this paper, all team members did their share and contributed equally." Meghan, Laura, and Cathy's experience was similar to a community of practice. Lahenius (2012) asserted that students' experiences in communities of practice may be illustrated the following themes: "belonging to a scientific community, academic development, and the experience of support from student peers" (p. 35). Furthermore, these communities of practice encompass multiple relationships that take place within social environments and among peers with shared scholarly interests (Lahenius, 2012). In this study, Meghan, Laura, and Cathy experienced a community of practice that was developed around scholarly and academic goals. They felt a belonging to a group where each could develop academically, professionally, and personally. Not only did this community of practice provide support through the comprehensive exam and dissertation stage, but support continued as peers collaborated on scholarly publications, presentations, and professional goals. The peers' professional backgrounds varied; however, their shared scholarly interests provided ways for their organic collaborative efforts to continue.

\section{Theme Four - Intentional Relational Learning}

Previous efforts have been made to use intentional relational learning to increase doctoral student success. Intentional relational learning includes opportunities for faculty and students to interact

and learn with one another in settings that are collaborative and may not only occur in an academic setting. For example, faculty can create intentional opportunities for social and collaborative interaction between faculty and students and peer to peer. Relational learning is based on the theory of social constructivism where learning is reciprocal and ideas are freely shared (The Taos Institute, n.d.). "Evidence demonstrates that a primary focus on student learning that incorporates intentional relational practice has increased student persistence and graduation and enriched faculty work lives" (Holloway \& Alexandre, 2012, p. 85). Through inclusion of these intentional relational practices, students and faculty "interact with and empower each other" to create communities that consist of "mutually beneficial and respectful learning as opposed to programs based on peer competition and isolation" (Holloway \& Alexandre, 2012, p. 89).

In the peers' narrative study of organic collaboration, intentional relational practices became a part of the process, but were not initially intentional. After the instructor-identified team experience previously described, the peers continued collaborating while studying for their comprehen- 
sive exams. The beginning of the study period took place in a purely academic setting. The study sessions then moved to more informal settings, such as restaurants and houses. This was described by Laura as: "Since the days on the fourth floor of the University library, we have met countless times to study, discuss, research, and have fun. So glad to be part of this team." After successful completion of comprehensive exams, Meghan, Laura, and Cathy continued to collaborate and created intentional relational practices throughout the dissertation process. As peers, they provided support, assistance, and encouragement to one another throughout the process which resembled the intentional relational practices as described above (Holloway \& Alexandre, 2012). Even though, the three peers were on different timelines toward completion of their dissertations, they were able to celebrate and derive encouragement from each other's previous successes.

An unintentional outcome of the organic collaboration was that as a team, the collaboration and support went beyond the comprehensive exams; it continued into the dissertation phase with a great deal of informal interaction. Laura alluded to the social aspect of the team:

The team was supportive, understanding, and flexible; at times, funny. Although we differed in a variety of ways, we all enjoyed each other's company. We began to create informal relational opportunities where we could get together, drink some wine, eat some food, and collaborate.

The group members provided support, encouragement, and flexibility to each other. Each member of the group remained highly motivated and self-directed, while also understanding of the need for work/life balance. In addition to the support, the organic collaborative team provided opportunities for socialization, which ultimately strengthened their bond and commitment to each other. When the peers collaborated socially, this helped to relieve stress and anxiety while they worked towards scholarly and academic interests (Jairam \& Kahl, 2012). These social opportunities occurred at local restaurants, the three peers' homes, and on social media. Most of the social occasions involved the three peers, but some included other peers, faculty, and the peers' families as well. The peers found that each theme is not independent of each other. In order for organic collaboration to occur, each theme needed to be present and cumulatively build upon each other (Figure 1).

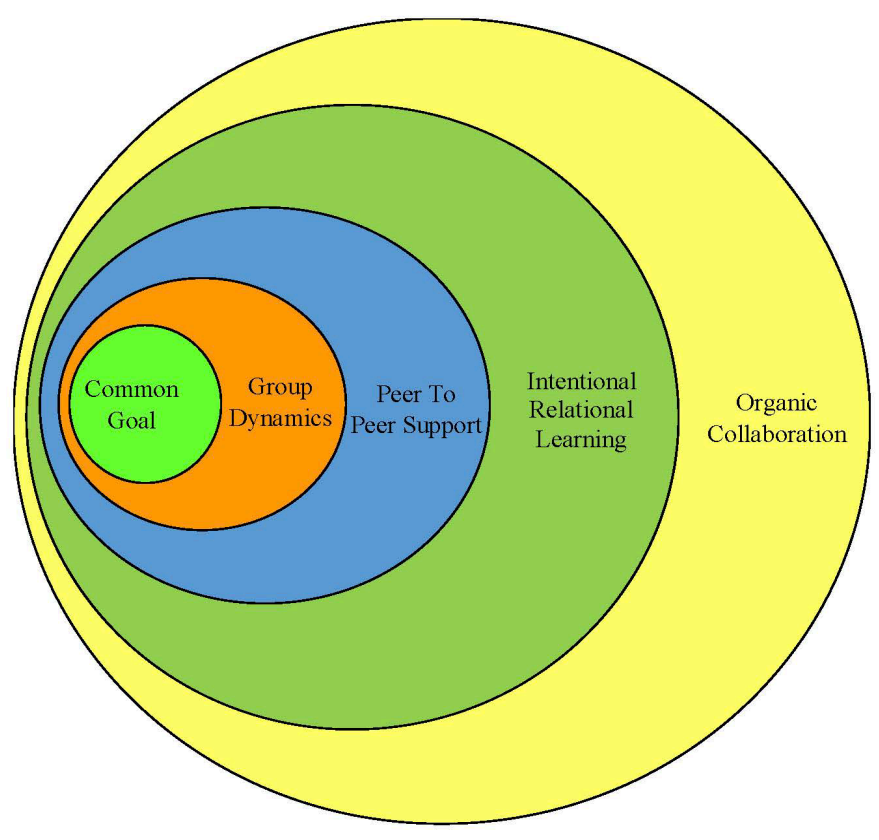

Figure 1: Nested Venn of Organic Collaboration 
As depicted in Figure 1, the common goal serves as the underpinning of the team and the key component to forming an organic collaborative team. As organic collaboration teams develop, they build on the foundation of common goal by identifying and recognizing their group dynamics. Amicable group dynamics of an organic collaborative team will help foster and enhance peer to peer support, which will transcend into practices of intentional relational learning. These themes provide the architecture of an organic collaborative team. This organic collaboration was an important factor in the three peers successfully completing their doctoral degrees, and also why they continue to work together as colleagues and friends.

\section{Implications}

Students, faculty, and higher education institutions can benefit from encouraging and supporting organic collaboration. As defined in this study, organic collaboration consists of four key themes: uniting for a common purpose, possessing amicable group dynamics, providing peer to peer support, and creating intentional relational learning. Given the statistics that less than $50 \%$ of students who enter a doctoral program persist to completion, leaders in higher education are compelled to find ways to improve these statistics.

To encourage organic collaboration, faculty have the ability to utilize team projects within the classroom environment. Meghan suggested: "As students progress through the program, faculty should provide the opportunity to self-select teams for some classes. This provides the students the opportunity to self-select peers as team mates." It is important to note, not all collaborations will be successful. As noted previously, successful collaborations consist of mutual respect, emotional engagement, and the ability to be creative and innovative (Campbell, 2011). Faculty and students can be encouraged to experiment and take risks when it comes to collaboration. In addition, since socialization has proven to be a significant factor in whether students persist in a doctoral program, students should be provided more opportunities to socialize both inside and outside the classroom. This socialization can occur by supporting program events, providing online platforms, and social media as ways for students to communicate and connect with peers.

Institutions can create a culture of collaboration where faculty and students are encouraged and supported in collaboration efforts. Laura suggested to "[p]rovide opportunities for students and faculty to come together and collaborate. Reward faculty for encouraging collaboration and creating collaborative environments for their students." Although faculty and institutions need to be supportive of organic collaboration, there also needs to be a balance and understanding of differing student needs.

Cathy suggested: "Faculty keep an eye out for groups that are forming organically, to hear their successes, and to think about how to guide other students to find possible groups." Although, Cathy advised: "for some doctoral students, independent learning is more their style. Faculty should be aware of those not forming an organic collaboration, because those individuals might need the extra support to make it through the program."

Peer to peer support should be recognized as an important factor that can positively impact doctoral completion. Devenish et al. (2009) recapped the experiences of a doctoral study group and how these positive experiences were not considered by the institution as a measure of postgraduate success. Devenish et al. (2009) proposed institutions recognize the value and application of peer to peer. Although Devenish et al. (2009) claimed the study group felt their experience was vital to their success, this was not recognized by the institution.

Consistent with Devenish et al. (2009), Meghan, Laura, and Cathy found their organic collaborative experience was a positive factor in their doctoral degree completion. Another consistency between the experience of Meghan, Laura, and Cathy when compared to the study as presented by Devenish et al. (2009), was that each other "remained engaged and enthusiastic with learning 
and with progress along the doctoral journey" (p. 60). Likewise, Flores-Scott and Nerad (2012) claimed peers were important to a doctoral learning program and had a positive impact on student learning, retention, and even the socioemotional development of students. Peers learned from each other and taught each other "what it means to be a student, a researcher, and an academic" (Flores-Scott \& Nerad, 2012, p. 77).

\section{Conclusion}

Through this narrative inquiry, Meghan, Laura, and Cathy learned the value of organic collaborative efforts went beyond expectations, and developed into a lifelong partnership to this day. Initially, they were placed on an instructor-identified team for the purpose of assignment completion. As the peers started their organic collaboration as a comprehensive exam study group, their original goal was to study together and prepare for the exams, and ultimately pass the comprehensive exams. However, the goal transformed to keep each member motivated, focused, and completing their doctorates. Meghan, Laura, and Cathy gained so much more than a study group and a doctorate.

As stated previously throughout this narrative inquiry, doctoral completion rates are around $50 \%$ (Jairam \& Kahl, 2012) and research is lacking on the impact of peer to peer support on completion rates (Flores-Scott \& Nerad, 2012). This narrative inquiry illustrated the impact of organic collaboration and peer to peer experiences of three peers as they successfully completed their part-time doctoral program. Further, the three peers defined, described, and recommended ways to encourage organic collaboration, which consisted of coming together for a common goal, having amicable group dynamics, providing peer to peer support, and creating intentional relational learning as illustrated in Figure 1. This organic collaborative team is an example of the long-term impact of collaboration and peer to peer support that continues through scholarly, professional, and personal experiences beyond doctoral program completion.

\section{References}

Amabile, T. M., Patterson, C., Mueller, J., Wojcik, T., Odomirok, P. W., Marsh, M., \& Kramer, S. J. (2001). Academic-practitioner collaboration in management research: A case of cross-profession collaboration. Academy of Management Journal, 44(2), 418-431.

Anderson, M. S. (1996). Collaboration, the doctoral experience, and the departmental environment. The Review of Higher Education, 19(3), 305-326.

Campbell, A. (2011, September 1). Collaboration is misunderstood and overused. Retrieved from http://blogs.hbr.org/2011/09/collaboration-is-misunderstood/

Conle, C. (2000). Narrative Inquiry: Research tool and medium for professional development. European Journal of Teacher Education, 23(1), 49-63. doi: 10.1080/713667262

Connelly, F. M., \& Clandinin, D. J. (1990). Stories of experiences and narrative inquiry. Educational Researcher, 19(5), 2 -14. doi: 10.3102/0013189X019005002

Council of Graduate Schools (2014). Ph.D. Completion Project. Retrieved July 14, 2014, from http://www.cgsnet.org/Ph.D.-completion-project

Creswell, J. (2006). Five qualitative approaches to inquiry. Thousand Oak, CA: Sage Publishing, Inc.

Creswell, J. W. (2007). Qualitative inquiry and research design: Choosing among five approaches. Thousand Oak, CA: Sage Publications, Inc.

Devenish, R., Dyer, S., Jefferson, T., Lord, L., van Leeuwen, S., \& Fazakerley, V. (2009). Peer to peer support: The disappearing work in the doctoral student experience. Higher Education Research and Development, 28(1), 59-70. doi: 10.1080/07294360802444362 
Flores-Scott, E. M., \& Nerad, M. (2012). Peers in doctoral education: Unrecognized learning partners. New Directions for Higher Education, 2012(157), 73-83. doi:10.1002/he.20007

Gardner, S. K. (2010). Contrasting the socialization experiences of doctoral students in high- and lowcompleting departments: A qualitative analysis of disciplinary contexts at one institution. Journal of Higher Education, 81(1), 61-81.

Holley, K., \& Caldwell, M. (2012).The challenges of designing and implementing a doctoral student mentoring program. Innovative Higher Education, 37(3), 243-253. doi:10.1007/s10755-011-9203-y

Holloway, E. L., \& Alexandre, L. (2012). Crossing boundaries in doctoral education: Relational learning, cohort communities, and dissertation committees. New Directions for Teaching \& Learning, 2012(131), 85-97. doi:10.1002/t1.20029

Jairam, D., \& Kahl Jr., D. H. (2012). Navigating the doctoral experience: The role of social support in successful degree completion. International Journal of Doctoral Studies, 7, 311-329. Retrieved from http://ijds.org/Volume7/IJDSv7p311-329Jairam0369.pdf

Jaschik, S. (2007, July). Why and when Ph.D. students finish. Inside Higher Ed, http://www.insidehighered.com/news/2007/07/17/Ph.D

Kania-Gosche, B., Leavitt, L., \& Wisdom, S. (2011, September 21). Changing practice in an Ed.D. program. Midwest Research to Practice Conference in Adult, Continuing, Community, and Extension Education. Lecture conducted from Lindenwood University, St. Charles, MO.

Lahenius, K. (2012). Communities of practice supporting doctoral studies. International Journal of Management Education, 10(1), 29-38. doi:10.1016/j.ijme.2012.02.003

Macke, C., \& Tapp, K. (2012). Teaching research to MSW students: Effectiveness of the team based learning pedagogy. Journal of Teaching in Social Work, 32(2), 148-160.

McLeod, L.E. (2010, November 8). Teamwork v. collaboration (and why I'm finally lifting my ban on sports analogies). Retrieved from http://www.huffingtonpost.com/lisa-earle-mcleod/teamwork-vcollaboration b 780213.html

Merriam, S. B. (1998). Qualitative research and case study applications in education. San Francisco, CA: Jossey-Bass Inc.

Mullen, C. A., \& Tuten, E. M. (2010). Doctoral cohort mentoring: Interdependence, collaborative learning, and cultural change. Scholar-Practitioner Quarterly, 4(1), 11-32.Retrieved from http://www.edint.com/

Patton, M.Q. (2002). Qualitative research and evaluation methods (3rd Ed.). Thousand Oaks, CA: Sage.

Pemberton, C. L. A., \& Akkary, R. K. (2010). A cohort, is a cohort, is a cohort ... or is it? Journal of Research on Leadership Education, 5(5), 170-208.

Radda, H. (2012). From theory to practice to experience: Building scholarly learning communities in nontraditional doctoral programs. Insight: A Journal of Scholarly Teaching, 7, 50-53.

Tarricone, P., \& Luca, J. (2002, July 7-10). Successful teamwork: A case study in quality conversations, Proceedings of the 25 HERDSA Conference, Perth, Western Australia, 640-646.

The Taos Institute. (n.d.) Creating promising futures through social constructivism. Retrieved from http://www.taosinstitute.net/relational-learning-in-education

Scarnati, J. T. (2001). On becoming a team player. Team Performance Management: An International Journal, 7(1/2), 5-10.

Storms, B. A., Prada, M. J., \& Donahue, E. N. (2011). Advising doctoral candidates to degree completion. Educational Leadership and Administration: Teaching and Program Development, 23, 85-92. 


\section{Biographies}

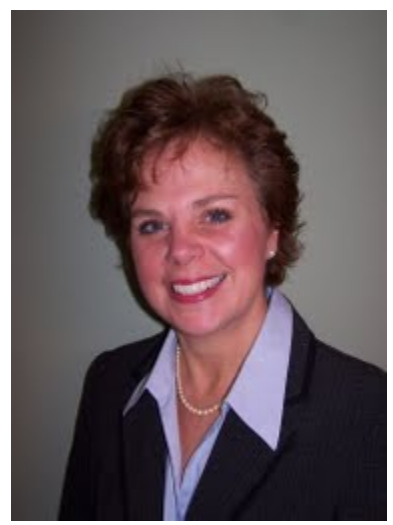

Cathy M. Littlefield, Ed.D. combines six years of higher educational experience along with 24 years in the hospitality and manufacturing industries, and business ownership to create a learning environment that is highly engaging. She holds the position of Associate Professor of Organizational Leadership and Management in Graduate Studies at Peirce College in Philadelphia. An entrepreneur by nature, she is innovative with learning modalities, educational technology, and course design which are geared toward the adult learner. Her research interests include hybrid course design, professional development, civic engagement and service learning, and improving the experience of the adult learner. Dr Littlefield earned a Doctorate in Education, Higher Education Academic Leadership from Widener University; Masters of Business Administration from West Chester University; and a Bachelor of Science in Hospitality Management from Widener University.

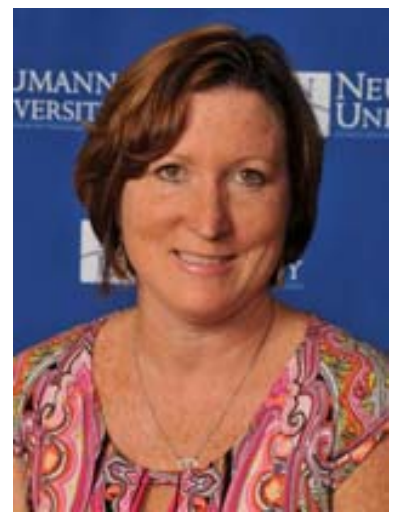

Laura M. Taddei, Ed.D. is currently an Assistant Professor of Education at Neumann University in Aston, PA, where she teaches undergraduate and graduate courses. She is a professional development speaker in both higher education and PreK-12 settings. Her research interests are in the area of teacher and faculty development, culturally responsive teaching, collaboration and peer to peer support, and educational technology. She has a Doctorate in Education from Widener University, a Masters in Education from Cabrini College, and a Bachelors in Organizational Dynamics and Human Performance Management from Immaculata University. Laura can be reached at taddeil@neumann.edu or on twitter@drlaurataddei.

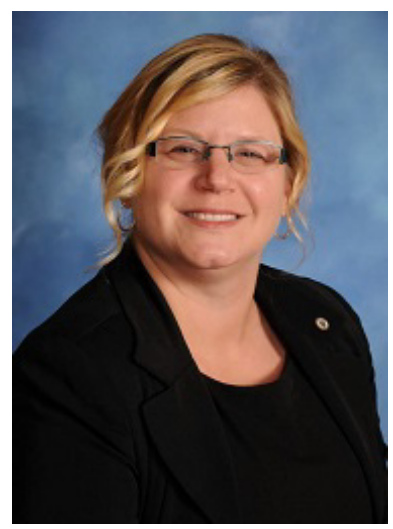

Meghan E. Radosh, Ed.D. is the Associate Director of Alumni Engagement at Widener University in Chester, PA. Since 2000, Meghan has been the project manager for Homecoming/Reunion Weekend, the annual Alumni Awards Celebration, and oversees alumni communication and social media outreach. She is an active member of CASE (Council for the Advancement and Support of Education) and serves as the CASE District II board Treasurer. Her research interests are higher education, onboarding, collaboration, and institutional advancement. Meghan has a Doctorate in Education, a Masters in Criminal Justice, and a Bachelors in Psychology from Widener University. 